\title{
MUNDOS QUE SE CRUZAM
}

\author{
ALBERTO SIMÕES, ANABELA BARREIRO, DIANA SANTOS, \\ RUI SOUSA-SILVA E STELLA E.O.TAGNIN
}

Preparar um livro de homenagem a Belinda Maia é, simultaneamente, uma satisfação e um desafio. E esse desafio reflete-se, não só no número e na qualidade das contribuições daqueles que quiseram e puderam prestar-lhe homenagem, mas também na escolha do próprio título deste livro. As 15 propostas diferentes que chegaram até nós revelam o entusiasmo e empenho que os autores e editores demonstraram nesta iniciativa. O título, "Linguística, Informática e Tradução: Mundos que se Cruzam", foi decidido depois de um processo de seleção pelos autores, de entre uma série de propostas cativantes, incluindo: Línguas sem fronteiras, As maravilhas da língua: What a wonderful word!, Belinda in language wonderland ou mesmo Belinda through the language-glass. Estes e outros títulos aludem à tradução, à criatividade linguística e ao fascinante domínio das línguas, inspirando-se nas obras de Lewis Carroll, Alice no País das Maravilhas e Alice do outro lado do espelho - obras queridas da Belinda. A lista poderia ser infindável, considerando que o contributo da Belinda para a ciência não se esgota nas línguas, tendo contribuído significativamente para a terminologia, a linguística e as tecnologias da linguagem humana, entre outras.

De um ponto de vista prático, e apesar de várias conversas prévias sobre o assunto, o livro começou de facto em junho de 2014 com a primeira chamada secreta, claro - de contribuições e com a discussão de ideias de como homenagear a Belinda. Fazer com que o projeto avançasse, mantendo simultaneamente secreta toda a iniciativa, dificultou um pouco as questões operacionais. Por exemplo, o financiamento ou publicação deste volume pela própria Universidade do Porto não foi possível pois, muito provavelmente, viria a ser descoberto. Esta é, aliás, a principal razão de este volume ser publicado por uma universidade estrangeira. Queremos, portanto, explicar que os colegas da Belinda na Universidade do Porto e no Centro de Linguística da Universidade do Porto deram o seu apoio e participaram ativamente e entusiasticamente nesta iniciativa, e que foi apenas a burocracia, junto com uma vontade dos editores de inovar e de manter a surpresa, que levou ao presente arranjo.

No decurso da preparação do presente volume, muitos outros colegas, alunos ou simplesmente admiradores da Belinda quiseram juntar-se mas, por diversas razões, não o conseguiram fazer. Para evitar omissões que pudessem ser mal interpretadas, decidimos não mencionar os muitos que, embora interessados, vieram a desistir em diferentes fases, sobretudo porque, devido ao critério de "top 
secret", poderemos ter, por lapso, deixado de informar muita gente que quereria e poderia ter participado. $O$ que é certo é que sabemos que este livro tem o apoio moral de muitos mais do que os autores que conseguiram contribuir nos prazos apertados que propusemos. Seja como for, agradecemos vivamente a todos os autores que não só apoiaram, mas que contribuíram com o seu texto e com as revisões dos outros artigos.

Poderíamos aqui descrever todo o processo de construção do livro, todas as fases, desde as chamadas de artigos até à recolha dos comentários, passando pelas decisões sobre formatação, línguas, transcrição, entre muitas outras tarefas que, motivados pela dedicação à Belinda, fomos realizando ao longo destes últimos meses; porém, essa descrição não nos parece relevante. $O$ único aspeto que parece necessário realçar é que a ordem pela qual apresentamos as contribuições é totalmente aleatória. Fizeram-se várias tentativas para agrupar os artigos em diferentes secções, mas a verdade é que tal seria limitar e contrariar a visão multidisciplinar deste grupo de pessoas inspiradas pela Belinda.

\section{LINGUÍSTICA, INFORMÁTICA E TRADUÇÃO}

Passamos a descrever muito rapidamente as diferentes contribuições. Vários foram os contributos centrados na tradução. Em "Tradução automática, ma non tropo", Anabela Barreiro discute duas tarefas da tradução automática que exigem a intervenção de especialistas linguísticos, a pré-edição de texto e a avaliação da tradução automática, tendo como objetivo realçar a importância do fator humano no processo de tradução automática. Este é um aspeto para o qual Belinda Maia tem chamado repetidas vezes a atenção. Por seu lado, a contribuição de António Teixeira et al., "Tradução automática na interação com máquina”, apresenta dois casos de aplicação ao português de tradução automática na área da interação entre os seres humanos e as máquinas: a conversão de informação sobre planos de medicação e o comando por voz.

Já na área do ensino da tradução, em "Ensinador paralelo: Alicerces para uma pedagogia nova", Diana Santos e Alberto Simões apresentam uma nova ferramenta de apoio ao ensino de tradutores que permite produzir exercícios baseados em traduções já feitas, estudando também quatro traduções de Lewis Carroll para o português.

Igualmente com ênfase no ensino de tradução, Stella E.O. Tagnin apresenta, em "Corpus-driven glossaries in translator training courses", um relato prático do recurso a uma abordagem orientada pelo corpo para a extração de terminologia em textos técnicos. Essa metodologia foi aplicada com bastante sucesso em várias ocasiões no Curso de Especialização em Tradução da Universidade de São Paulo, tendo alguns trabalhos resultado em publicações comerciais.

Num nível mais teórico, o artigo de Thomas Hüsgen, "Para uma ontologia dos Estudos de Tradução. Comentários sobre a proposta de S. Vandepitte (2008)", pro- 
põe um conjunto de sugestões para um "novo mapa coerente e consistente" dos estudos da tradução, a partir de quatro perspetivas: o acréscimo de termos, a identificação de outros níveis hierárquicos, a modificação de sinónimos e a sugestão de novas relações associadas.

Durante a tradução, um dos recursos mais úteis a um tradutor é o acesso a terminologia. Nessa direção, o artigo de Maria José Finatto, "Estudos de Terminologia no Brasil: diálogos com Portugal", contrasta artigos de autores brasileiros e portugueses, que abordam a identificação de terminologia a partir de corpos, salientando o papel fundamental que Belinda Maia teve como disseminadora dessa metodologia.

Em relação à extração de terminologia a partir de corpos, Françoise Bacquelaine apresenta a evolução do Corpógrafo, ferramenta idealizada pela própria Belinda, em "Corpógrafo, terminologie, phraséologie", de 2003 até 2008. Além disso, relata duas experiências do uso do Corpógrafo. Na primeira, estuda a neonímia comparada da terminologia Bluetooth em inglês, francês e português. Na segunda, aborda o uso dos quantificadores universais chaque/cada, tout/todo o e tous les/todos os em francês e em português de Portugal.

Sendo o Corpógrafo uma ferramenta baseada na análise e processamento de corpos, não é de estranhar que várias tenham sido as contribuições que fazem uso deste tipo de recurso para os mais diferentes estudos.

Augusto Soares da Silva apresenta um estudo comparativo do sucesso dos estrangeirismos em português europeu e português brasileiro. No seu artigo "Empréstimo lexical, conceptualização e variação: Para a abordagem sociocognitiva e socioletométrica dos estrangeirismos no português", o autor aplica o novo modelo sociocognitivo e socioletométrico do empréstimo lexical ao português como língua pluricêntrica, utilizando um corpo de textos nos domínios do futebol e da moda.

Por um lado, em "A admiração à luz dos corpos", Diana Santos e Cristina Mota estudam o campo da admiração em português com base nos corpos da Gramateca, inspirando-se na tese de doutoramento de Belinda Maia sobre as emoções em inglês e português. Por outro lado, Signe Oksefjell, em "Love and hate in English and Portuguese", faz um estudo do par love/hate também em inglês e português, inspirando-se no contraste entre o inglês e o norueguês feito há alguns anos por Stig Johansson.

Em "Pesquisa em educação: perspetivas (qualitativas?) na exploração de grandes corpora", Miriam Leite e Cláudia Freitas apresentam os resultados de dois estudos baseados em corpos aplicados à investigação educacional: um corpo de blogues criado e mantido por escolas públicas e um outro, de materiais de ensino, usado em escolas públicas, chamando a atenção para as potencialidades do uso de corpos no estudo da educação, ao mesmo tempo referindo alguns perigos do uso acrítico de ferramentas apenas quantitativas. 
Um estudo eminentemente cultural associado à representação de um país na imprensa de outro é o artigo de Luís Costa "O Japão visto de Portugal - Exploração usando um corpo de textos jornalísticos", que é, como o nome indica, um estudo exploratório extraindo informações de um jornal. O artigo de Carla Abreu, Jorge Teixeira e Eugénio Oliveira, por seu lado, usa um corpo jornalístico para criar automaticamente novas histórias, em "Construção automática de histórias a partir de notícias", e é um bom exemplo de uma área ou preocupação que a Belinda sempre defendeu: aplicações concretas graças ao progresso tecnológico.

Para que os estudos mencionados acima sejam possíveis é necessária a existência de corpos. Nessa vertente, algumas contribuições relatam problemas e desafios na sua construção.

Em "Automatic anonymization of a new Portuguese-English parallel corpus in the legal-financial domain", Eckhard Bick e Anabela Barreiro apresentam um novo corpo paralelo português-inglês do domínio jurídico-financeiro, em que realizaram a anonimização de entidades mencionadas para efeitos de preservação da privacidade e proteção de dados, uma questão importante que merece mais reflexão na área da tradução.

Já Sílvia Araújo e Ana Correia, em "Estudo preliminar da anáfora num corpus de interpretação", apresentam o processo de compilação de um corpo multimédia bidirecional inglês-português - o "Corpo de Interpretação/Per-Fide" - e discutem resultados preliminares referentes às relações anafóricas em dados autênticos de interpretação simultânea. Como a anáfora é uma área crítica dessa atividade profissional, as autoras destacam a contribuição que a exploração desse corpo pode trazer para a formação de intérpretes simultâneos.

O estudo da língua não pode esquecer os fundamentos linguísticos. Nesse sentido, em "Activities with culmination", Fátima Oliveira e António Leal propõem um novo tratamento de um fenómeno aspetual, sugerindo a existência de três tipos de verbos em português: os que no seu significado lexical incluem um ponto final (télicos), os que não o incluem nem podem incluir (atélicos) e os - proposta nova - alfatélicos, que podem ou não corresponder a um processo culminado.

Já no seu estudo sobre a sintaxe do português, Ana Maria Brito questiona se o português europeu tem alternância dativa. Em "Two base generated structures for ditransitives in European Portuguese", a autora recorre ao estudo de certos factos de ordem de palavras, anteposição, ligação e escopo, concluindo que, embora num sentido distinto do de outras línguas, esta língua tem alternância dativa.

Concentrando-se, por sua vez, no oral, João Veloso estuda as mudanças operadas nos róticos do português, em "Here come the English Rs! The never ending story of Portuguese rhotics". Utilizando o corpo do Arquivo Dialetal do Centro de Linguística da Universidade do Porto, o autor procura identificar e datar mudanças menos estudadas nesta classe consonântica do português. 
Mas a comunicação humana inclui, ainda, outras áreas, como o artigo "A tool at hand: gestures and rhythm in listing events - Case studies of European and African Portuguese speakers" demonstra. Isabel Galhano Rodrigues descreve um estudo etnográfico de gestos e linguagem corporal em interação. Baseando-se num corpo de quatro interações de falantes de diferentes culturas, a autora analisa aspetos morfológicos e padrões rítmicos como forma de deteção de regularidades e diferenças (culturais) dos gestos.

Como a Belinda propôs e estudou, enquanto pioneira com base em corpos, uma das funções da linguagem é exprimir emoções e sentimentos. Se na comunicação oral e presencial é possível tirar partido da linguagem corporal e da entoação, na comunicação escrita esse sentimento torna-se mais complicado de detetar, sendo a área de deteção de sentimento por computador uma das mais movimentadas neste momento.

Assim, Brett Drury e Alneu Lopes, em "The identification of indicators of sentiment using a multi-view self-training algorithm", escrevem sobre a identificação de sentimento usando algoritmos de aprendizagem, em que os resultados atingiram níveis de $70 \%$ de precisão.

Também relacionado com este tópico, em "SentiLex-PT: Principais características e potencialidades", Paula Carvalho e Mário Silva apresentam um léxico com informação de sentimento e demonstram a sua aplicação em dois corpos distintos.

Não só este tipo de estudo pode tirar partido de ontologias, área que sempre esteve entre as preferidas da Belinda. Em "As Wordnets do Português", Hugo Gonçalo Oliveira et al. apresentam várias das WordNets existentes para o português, discutindo as suas principais diferenças e semelhanças, e discutindo de que forma estas iniciativas podem criar sinergias na melhoria dos respetivos recursos.

Finalmente, e voltando ao campo das aplicações e estudo de textos concretos, o artigo de Pavel Brazdil et al., "Affinity mining of documents sets with network analysis enriched by keywords and summaries", apresenta algumas experiências de uso de algoritmos de minagem de textos para detetar similaridades entre documentos. Por seu turno, em "'Reporter fired for plagiarism': a forensic linguistic analysis of news plagiarism", Rui Sousa-Silva deteta outro tipo de similaridades mais problemáticas, nomeadamente no campo do plágio jornalístico. Recorrendo a casos ocorridos nos últimos anos, o autor mostra que o texto noticioso é, frequentemente, objeto de plágio, e ilustra de que modo uma abordagem linguística de natureza forense a permite detetar. 
DEDICATÓRIAS

Dando a palavra aos editores:

Conheci pessoalmente a Belinda em terras estranhas, no LREC $2002 \mathrm{em}$ Palma de Maiorca, e desde logo fui contagiada pelo seu entusiasmo e vontade de contribuir para melhorar o panorama da linguística computacional em Portugal, mais surpreendente ou comovente por ela ser inglesa e não portuguesa. "Caímos nos braços uma da outra», como se diz em bom português (mas obviamente não literalmente) e desde aí desenvolvemos uma relação profissional e de amizade de que muito me orgulho. Penso que como lusofalantes não nos devemos envergonhar de reconhecer que uma das pessoas em Portugal que mais fez pelos estudos de tradução, pelos estudos contrastivos, e pela linguística computacional no nosso país foi uma inglesa do Porto. Esta homenagem é pois o mínimo que me parece natural fazer-lhe. Mais fizera, não fosse tão curto o prazo que tivemos para produzir este livro.

Diana Santos

Caríssima Belinda, já nem sei mais quando nos conhecemos. Se não me falha a memória foi no I CULT em Bertinoro, nos idos de 1997. Que conferência excelente! Já lá percebi que tínhamos abordagens similares no nosso trabalho com os alunos de tradução. A partir daí mantivemos contato estreito e em 1998 estiveste em São Paulo para uma conferência da ABRAPT. Em 2002 tive o prazer de ter uma contribuição sua para os Cadernos de Tradução, da UFSC, num número especial sobre Linguística de Corpus. Em 2003 cruzamos no Corpus Linguistics em Lancaster e você nos proporcionou um belíssimo tour pela countryside inglesa - era seu aniversário, lembra? Nosso convívio maior foi em 2004. Você se recorda do congresso da ABRAPT em Fortaleza, precedido por aquele maravilhoso fim-de-semana em Guajiru? Inesquecivel, né? Em compensação, como fizemos você trabalhar naquele congresso! No mesmo ano apresentamos um trabalho - Ideias que cruzam o oceano no congresso da EST, em Lisboa, abordando nossos pontos em comum. Foi quando você, gentilmente, nos convidou, a mim e ao Franco, para ficar em sua casa e nos ciceroneou pelo norte de Portugal. Que maravilhosa guia e motorista você é! Lamento apenas que estejamos em lados opostos do Atlântico. Como eu gostaria de ter tido a oportunidade de trabalhar mais de perto com você, uma pesquisadora admirável, eclética, generosa, mas "pé-no-chão", sempre procurando desenvolver estudos e ferramentas (leia-se Corpógrafo) que tenham aplicação prática na tradução e na terminologia. Curta muito sua aposentadoria. 
No momento da sua jubilação, não poderia deixar de prestar homenagem a uma mestre insigne da tradução em Portugal, a professora Belinda Maia. Faço-a por meio de dois artigos, um sobre a anonimização de entidades mencionadas num corpus de tradução profissional do domínio jurídicofinanceiro, o outro sobre as tarefas de pré-edição de texto a ser traduzido automaticamente e avaliação da tradução computorizada, ambas exigindo a participação de especialistas nas línguas envolvidas na tradução. A carreira académica da professora Belinda Maia foi dedicada essencialmente ao ensino da tradução em Portugal, país que escolheu para viver e trabalhar, onde a sua obra na área da linguística contrastiva e tradução deixa uma marca indelével. Como sua antiga aluna de doutoramento, tive o privilégio de testemunhar de perto o seu rigor científico e a sua genuinidade e usufruir da generosidade com que compartilha a sua sabedoria com os seus alunos e colegas de profissão. Que esta singela homenagem permita simbolizar a paixão com que defende o envolvimento de linguistas e tradutores profissionais no processo de tradução automática.

Anabela Barreiro

Who's to say what's proper? What if it were agreed that "proper" meant wearing a codfish on your head? Would you wear it?

-Lewis Caroll, Alice in Wonderland

Passaram-se mais de 20 anos desde que conheci a Professora Belinda Maia, como estudante do terceiro ano de tradução da Faculdade de Letras da Universidade do Porto. Foi numa dessas primeiras aulas que, para grande perplexidade de muitos, a Belinda aplicou à tradução uma lição de vida à qual poucos estavam habituados: "There is no black and white in translation studies." Desde esta lição de tradução - e de vida - a minha admiração pessoal e profissional pela Belinda não parou de crescer. Pela sua energia. Pela sua coragem. Pela sua enorme capacidade de trabalho. Pela sua diplomacia. Pela sua capacidade de quebrar barreiras convencionais. E, sobretudo, pelo seu rasgo. Naquela tarde de 1994, ainda desconhecia que os dois partilharíamos um longo caminho, primeiro na orientação do estágio de Licenciatura, depois na orientação do Mestrado, e, mais tarde, na co-orientação do Doutoramento, tal como desconhecia que aquela Professora me apoiaria em muitos dos desafios e dilemas, intelectuais e profissionais, com os quais me viria a defrontar no meu percurso. Neste momento importante da sua vida, não poderia deixar de lhe prestar homenagem. Faço-o em meu nome e em nome de todos os meus colegas cujas vidas a Belinda tocou e que, por alguma razão, não participam neste volume. Mas faço-o sobretudo pela amizade que partilhamos. 


\section{A GRADECIMENTOS}

Agradecemos ao CLUP, na pessoa do seu diretor, João Veloso, o apoio financeiro prestado para a edição do presente volume. Agradecemos também ao ILOS, da Universidade de Oslo, o apoio financeiro prestado para a publicação em papel.

Obrigado aos editores da OSLa, Atle Grønn e Dag Haug, a presteza na ajuda e na facilitação dos prazos, que foram muito apertados, e ao Nuno Carvalho pela grande ajuda na conversão e formatação dos artigos.

O nosso maior agradecimento vai para todos os que participaram nesta iniciativa, como autores, e como parceristas.

CONTACTOS

Alberto Simões

Linguateca e CEH, Universidade do Minho

ambs@ilch . uminho.pt

Anabela Barreiro

INESC-ID e Linguateca

anabela.barreiro@inesc-id.pt

Diana Santos

Linguateca e Universidade de Oslo

d.s.m.santos@ilos.uio.no

Rui Sousa-Silva

Centro de Linguística da Universidade do Porto

r.sousa-silva@lflab.pt

Stella E.O. Tagnin

Universidade de São Paulo

seotagni@usp.br 